\title{
Nutritional

\section{Impact of storage conditions on the health promoting attributes of lemon, Citrus limon juice}

\author{
Dhinesh Kumar $\mathrm{V}^{1 *}$ and D. Ramasamy \\ ${ }^{1}$ Department of Food Science and Technology, CFDT, TANUVAS, Chennai-52. Professor and Head, \\ Department of Food science and Technology
}

\begin{abstract}
Consumers are increasingly expecting the fruits to be tasty and attractive while being safe and healthful. The objective of the present study was to develop a lemon drink and to see the effects of different storage temperatures, presence of gasses and storage period over the bio-chemical quality of the drink. In the preparation of lemon drink, volume of lemon juice (Citrus limon) (10\%), sugar (11\%) and water (79\%) were used. Lemon juice was filled in sterilized glass bottles, sealed and Pasteurized at $850 \mathrm{C}$ for 15 minutes and stored at $37 \mathrm{oC}$ and $60 \mathrm{C}$ with and without vacuum for 150 days. Biochemical changes in lemon drink were investigated after each 30 days for the period of 150 days. Following chemical parameters of fruit juice were determined : total soluble solid (TSS), acidity, $\mathrm{pH}$, moisture, ash content, carbohydrate, protein, fat and ascorbic acid were quite similar for both varieties. The dark yellow color of lemon cultivar had eye appeal effect to the consumers. With the various nutritional benefits, the fruits could be recommended for commercial exploitation and preparation of different value added products. A gradual increase in acidity, total soluble solids, reducing sugars and total sugars was observed in all samples, while $\mathrm{pH}$ and ascorbic acid decreased gradually during storage studies. The declining trend in ascorbic acid contents of lemon drink was increased as a function of product storage. The overall results showed that samples without presence of gasses (sealed with vacuum) at $6^{\circ} \mathrm{C}$ gave best results for ascorbic acid retention.
\end{abstract}

KEY WORDS: LEMON DRINK, ASCORBIC ACID RETENTION, BIO-CHEMICAL PROPERTIES

\section{INTRODUCTION}

Fruits and vegetables are important sources of essential dietary nutrients such as vitamins, minerals and fibers. Since the moisture content of the fresh fruits and vegetables is more than $80 \%(\mathrm{wb})$; they are classified as highly perishable commodities. The overall world's fruits production was about $609,213,509$ metric ton in 2010 (FA0, 2010). According to the estimates, nearly 30\% of the fruits are lost due to spoilage, mishandling, during transportation and lack of cold storage and processing techniques (Singh et al., 1994). Fruit juice preservation has an important role in the conservation and better utilization of fruits and vegetables in order to avoid the

\section{ARTICLE INFORMATION:}

*Corresponding Author: dhineshfpe@gmail.com

Received $5^{\text {th }}$ February, 2016

Accepted after revision $28^{\text {th }}$ March, 2016

BBRC Print ISSN: 0974-6455

Online ISSN: 2321-4007

Thomson Reuters ISI SCI Indexed Journal

NAAS Journal Score : 3.48

- A Society of Science and Nature Publication, 2016. All rights reserved.

Online Contents Available at: http//www.bbrc.in/ 
glut and utilize the surplus during the off-season. It is necessary to employ modern methods to extend storage life for better distribution and also processing techniques to preserve them for utilization in the off-season. The fruit can be preserved by converting it into products like jam, jelly, fruit bar, juice, pickle and murabba to prolong their utilizable lifespan. Fruit juice preservation has an important role in the conservation and better utilization of fruits and vegetables in order to avoid the glut and utilize the surplus during the off-season. It is necessary to employ modern methods to extend storage life for better distribution and also processing techniques to preserve them for utilization in the off-season. The fruit can be preserved by converting it into products like jam, jelly, fruit bar, juice, pickle and murabba to prolong their utilizable lifespan. Fruit juicing is one of the easiest way to preserve fruit, (Vidhya and Narain, 2011; GonzalezMolina et al., 2010; Mulero et al., 2012; Opera, 2015).

The production of fruit and vegetable juices is important both from the human health and commercial standpoints. The availability of nutritious components from fruits and vegetables to a wide range of consumers is thus facilitated throughout the year by the marketing of their juices. The production process of fruit and vegetable juices includes steps like extraction, clarification, and stabilization (Bhat, 2000).

Citrus fruits are among the most important horticultural crops, lemon (Citrus limon L.) being the third most important citrus crop species (Gonzalez-Molina et al., 2010). Several studies have pointed out that lemon is a rich source of nutrients and phytochemicals, including flavonoids, citric acid, vitamin C, and minerals (Gonzalez-Molina et al., 2008), which have numerous health promoting properties (Gonzalez-Molina et al., 2010; Mulero et al., 2012).

For this reason, lemon juice is an interesting food matrix for designing new beverages, as well as being a suitable source of value-added products since overproduction and non-marketable fruits lead to a serious environmental problem of un-used agro waste on a yearly basis. In this regard, lemon juice represents an alternative for the conversion of a bio-burden into a food product. Lemon juice has a high antioxidant capacity due to the presence of citrate, vitamin C, vitamin $\mathrm{E}$ and flavonoids such as eriocitrin, hesperetin (Miyake et al., 1998) and limonoids (Yu et al., 2005). The main objective of this study was to observe the effect of different storage conditions on the bio-chemical quality, especially on ascorbic acid content of the lemon drink.

\section{MATERIAL AND METHODS}

The fresh lemon fruits, Citrus limon of Sarbati variety were purchased from market. The fully ripened, healthy and uniform size fruits were selected. The fruits were washed, peeled and cut into two equal parts. The juice was extracted manually and filtered through muslin cloth to remove rags and seeds (Fig 1).

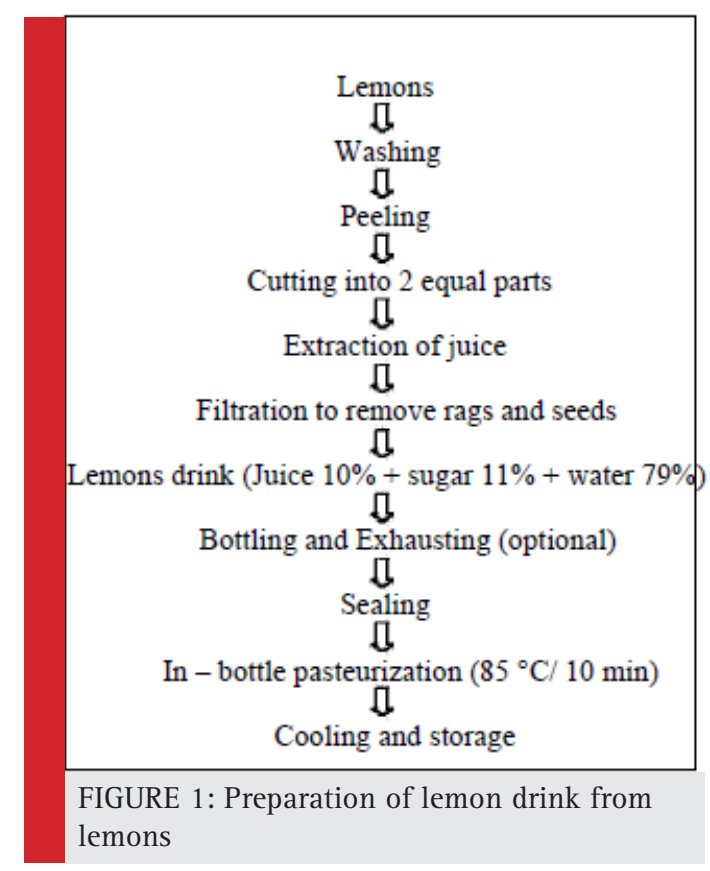

In lemon drink preparation, levels of lemon juice, sugar and water have been optimized by preliminary trials. Citric acid was also added as preservative in lemon drink. Lemon drink was bottled with and without exhausting. After bottling, bottles were pasteurized at 85 ${ }^{\circ} \mathrm{C}$ for 15 minutes. Pasteurized bottles were cooled and stored $\left(6^{\circ} \mathrm{C}\right.$ and $\left.37^{\circ} \mathrm{C}\right)$ up to the storage period of 150 days. The bio-chemical parameters of the samples evaluated after each 30 days interval. The obtained data were analysed for statistical significance. Four types of lemon drink samples have been prepared. For samples $T_{1}$ and $\mathrm{T}_{3}$ exhausting has been used before bottling and stored at $6^{\circ} \mathrm{C}$ and $37^{\circ} \mathrm{C}$ temperature respectively and samples $T_{2}$ and $\mathrm{T}_{4}$ bottled without exhausting and stored $6^{\circ} \mathrm{C}$ and $37^{\circ} \mathrm{C}$ temperature respectively.

The titratable acidity of fresh lemon drink samples was determined as per the procedure described by Ranganna (1986). Aliquot of the samples were diluted with distilled water and then titrated with $0.1 \mathrm{~N} \mathrm{NaOH}$ using $1 \%$ phenolphthale in solution as indicator. The percent acidity (as citric acid) as was calculated using following formulae.The $\mathrm{pH}$ of lemon drink was determined by using digital $\mathrm{pH}$ meter (Make: Elico LI 610). The $\mathrm{pH}$ meter was standardized with distilled water of $\mathrm{pH} 7.0$ and standards at $\mathrm{pH} 4.0$ and $\mathrm{pH}$ 9.0.

The total soluble solids content of the lemon drink was directly measured by using digital hand refractom- 
eter (Make: ATAGO hand refractometer). Ascorbic acid in lemon drink at different stages of storage was determined according to AOAC method (AOAC, 1995). Lemon drink of $2 \mathrm{~mL}$ was taken in a conical flask and blended with $20 \mathrm{~mL}$ of metaphosphoric-acetic acid solution to extract ascorbic acid. The mixture was filtered using a Whatman filter paper and transferred to a volumetric flask. $2 \mathrm{~mL}$ of the filtrate extract with $5 \mathrm{~mL}$ metaphorsphoric- acetic acid solution was rapidly titrated with 2 , 6 dichlorophenol indophenol solution until light distinct rose pink colour persisted for more than $5 \mathrm{sec}$.

Reducing sugar content of lemon drink samples was also determined using Lane and Eynon method (Ranganna, 1986) in which $5 \mathrm{~mL}$ of clarified lemon drink was transferred in to a $250 \mathrm{~mL}$ flask. About $100 \mathrm{~mL}$ of distilled water was added and solution was neutralized with $1 \mathrm{~N} \mathrm{NaOH}$ solution using phenolphthalein as the indicator. Two $\mathrm{ml}$ of lead acetate solution was added to the flask and shaken. It was made to stand for 10 min. Necessary amount of potassium oxalate solution was then added to remove the excess lead present in the sample. The solution was then made up to $250 \mathrm{~mL}$ using distilled water, filtered and used for the estimation of total reducing sugar. A solution containing equal volume of Fehling reagents A and B was titrated against the sample solution and the amount of reducing sugar present in $100 \mathrm{ml}$ of juice was estimated as per the procedure described by Ranganna (1986).

Total sugar contents of the lemon drink samples were determined using Lane and Eynon method (Ranganna, 1986). For total sugar determination, five $\mathrm{ml}$ of clarified aonla juice was taken in a $250 \mathrm{ml}$ conical flask and 50 $\mathrm{ml}$ distilled water was added to it. About $5 \mathrm{~g}$ of citric acid was then added and boiled for 10 minutes for the inversion of sugar. The resulting solution was then neutralized with $1 \mathrm{~N} \mathrm{NaOH}$ solution using phenolphthalein as the indicator. The chemical used for the titration was a mixture of Fehling solution A and B. This solution was titrated against the sample solution and the amount of total invert sugar present in $100 \mathrm{ml}$ of juice was estimated as described by Ranganna (1986). Data were analyzed statistically (ANOVA) using analysis of variance and differences among the means were determined for significance at $\mathrm{P}<0.01$ using commercial statistical package, Design Expert - version 8.0.7.1.

\section{RESULTS AND DISCUSSION}

Acidity is also an important attribute because tartness is a major factor in the acceptability of lemon drink. Acid gives the characteristic sourness to the product. Citric acid is the major acid in the lemon juice that enhances the characteristic flavour of the lemon drink. The data regarding acidity of different treatments of lemon drink is presented in Table 1. Highest acidity i.e. 0.389 was recorded in sample $\mathrm{T}_{4}$ (bottled without exhausting and stored at $37^{\circ} \mathrm{C}$ ), while lowest i.e. 0.315 was observed in $\mathrm{T}_{1}$ (bottled with exhausting and stored at $6^{\circ} \mathrm{C}$ ). There was a gradual increase in acidity in all treatments during storage up to 150 days (Fig 2). However significant variation in acidity was observed during the storage of 150 days. This increase in acidity was attributed to the degradation of sugar into carboxyl acids.

The $\mathrm{pH}$ has great importance to maintain self stability of the lemon drink. $\mathrm{pH}$ can also influence the flavour and processing requirements of the beverage. The data regarding $\mathrm{pH}$ of different treatments of lemon drink is presented in Table 1. Storage intervals also influenced the $\mathrm{pH}$ of the beverage. A decline in $\mathrm{pH}$ towards acidic region was noticed as the storage of the lemon drink increased. However, significant variation in $\mathrm{pH}$ was observed during the storage of 150 days (Fig 3). This decrease in $\mathrm{pH}$ was attributed to formation of acidic compounds by degradation of reducing sugars, as discussed by Zia (1987). Similar trend of decrease $\mathrm{pH}$ was also reported by Saleem (1980).

The data on total soluble solids (TSS) for all treatments has been presented in Table 1. Total soluble solids of all the samples of lemon drink increased during the storage period of 150 days. However, significant variation in TSS was observed during the torage period of 150 days. Maximum TSS i.e. $13.9^{\circ}$ brix was found in the sample $\mathrm{T}_{4}$, that was bottled without exhausting and stored at $37^{\circ} \mathrm{C}$. Whereas, minimum TSS i.e. $13.4^{\circ}$ brix was found in sample $\mathrm{T}_{2}$ that was bottled without exhausting and stored at $6^{\circ} \mathrm{C}$ (Fig 4). This increase in TSS in all the samples of the lemon drink during storage period of 150 days, might be due to formation of pectic substances from protopectin and monosaccharides from disaccharides i.e. degradation of sucrose into glucose and fructose. Similar results have been reported by Sarolia and Mukherjee (2002) in their studies on the lime juice. These results are also connecting with previous studies of Kaunjoso and Luh (1967), while studying on the canning and storage of oranges and in canned peaches.

Ascorbic acid content of all samples of lemon drink decreased during the storage period of 150 days. Ascorbic acid content decreased at faster rate for sample $\mathrm{T}_{3}$ (bottled with exhausting and stored at $37^{\circ} \mathrm{C}$ ) and $\mathrm{T} 4$ (Bottled without exhausting and stored at $37^{\circ} \mathrm{C}$ ) then samples $\mathrm{T}_{1}$ (bottled with exhausting and stored at $6^{\circ} \mathrm{C}$ ) and T2 (bottled without exhausting and stored at $6^{\circ} \mathrm{C}$ ). After storage period of 150 days, the retention of the ascorbic acid was $0.468,0.421,0.411$ and $0.394 \mathrm{mg} / 100 \mathrm{gm}$ for samples $\mathrm{T}_{1}, \mathrm{~T}_{2}, \mathrm{~T}_{3}$ and $\mathrm{T}_{4}$ respectively (Fig 5). Statistical analysis showed that the results are highly significant 


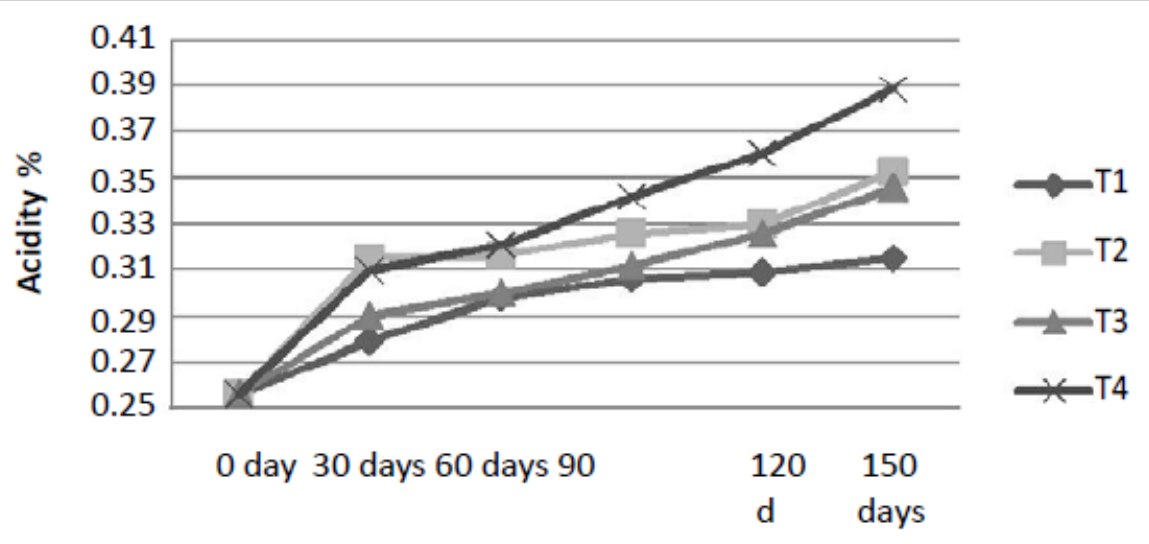

FIGURE 2: Changes in acidity content of samples during storage period

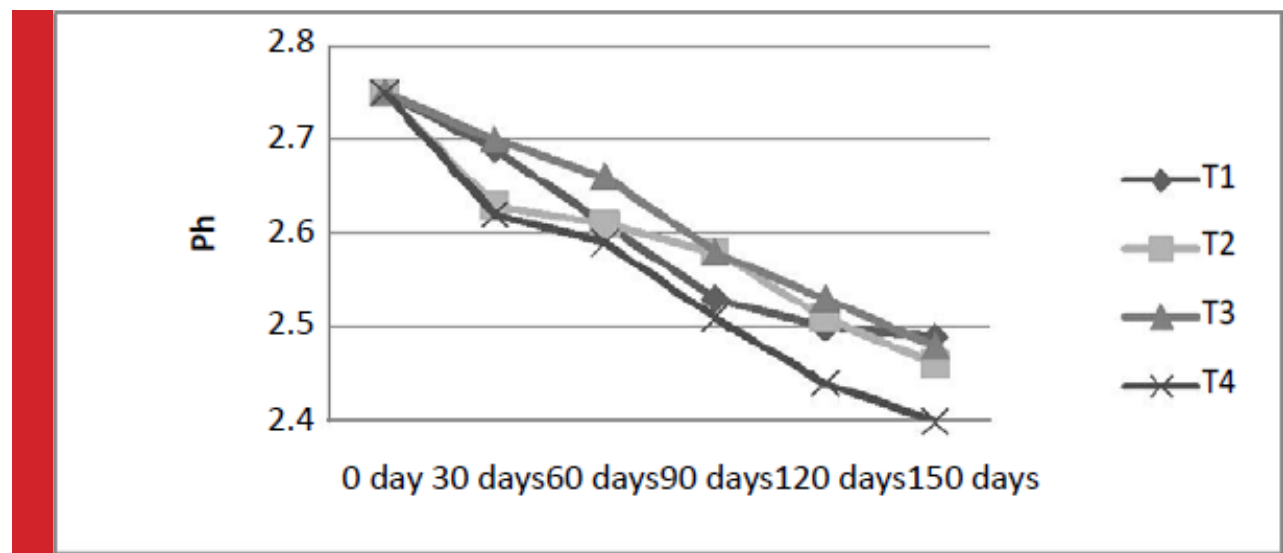

FIGURE 3: Changes in $\mathrm{pH}$ of samples during storage period
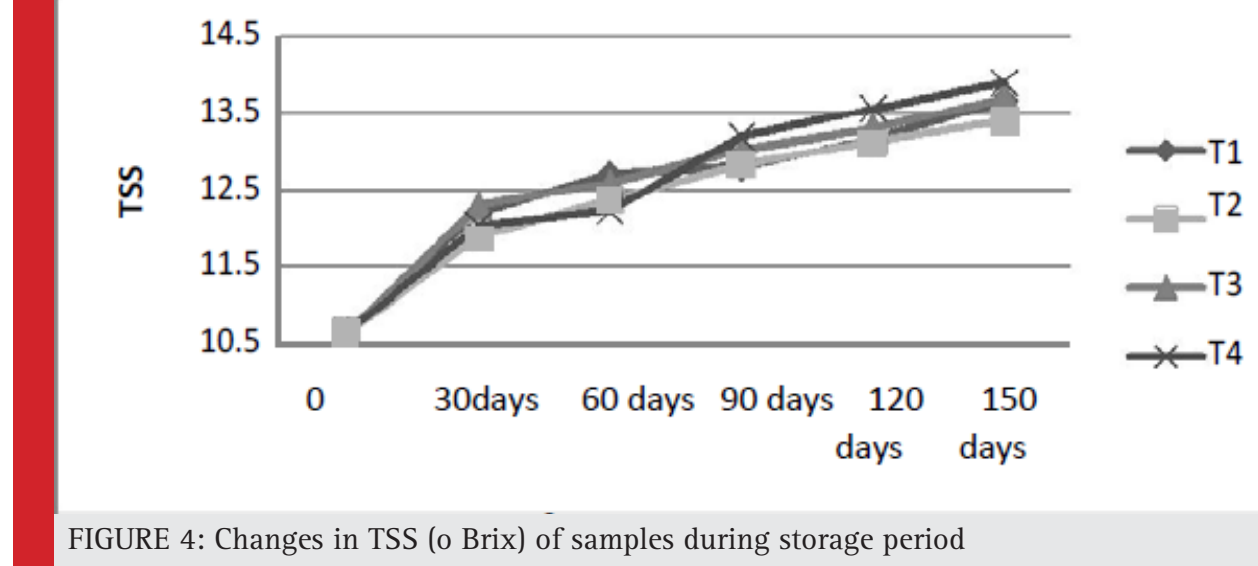

FIGURE 4: Changes in TSS (o Brix) of samples during storage period 


\begin{tabular}{|c|c|c|c|c|c|c|c|}
\hline Treatments & $\begin{array}{l}\text { Storage (Days) } \\
\text { Parameters }\end{array}$ & 0 & 30 & 60 & 90 & 120 & 150 \\
\hline \multirow{6}{*}{$\mathrm{T} 1$} & Acidity & 0.254 & 0.277 & 0.297 & 0.308 & 0.307 & 0.312 \\
\hline & $\mathrm{pH}$ & 2.76 & 2.67 & 2.62 & 2.55 & 2.52 & 2.46 \\
\hline & TSS ( ${ }^{\circ}$ Brix) & 10.61 & 12.4 & 12.6 & 12.6 & 13.13 & 13.64 \\
\hline & Ascorbic acid & 2.62 & 2.56 & 0.495 & 0.484 & 0.468 & 0.466 \\
\hline & Reducing Sugar & 2.02 & 2.07 & 2.18 & 2.21 & 2.23 & 2.32 \\
\hline & Total Sugar & 2.33 & 2.34 & 2.41 & 2.47 & 2.51 & 2.52 \\
\hline \multirow{6}{*}{$\mathrm{T} 2$} & Acidity & 0.256 & 0.315 & 0.316 & 0.326 & 0.33 & 0.353 \\
\hline & $\mathrm{pH}$ & 2.75 & 2.63 & 2.61 & 2.58 & 2.51 & 2.46 \\
\hline & TSS $\left({ }^{\circ}\right.$ Brix $)$ & 10.64 & 11.9 & 12.37 & 12.83 & 13.13 & 13.4 \\
\hline & Ascorbic acid & 2.63 & 1.58 & 0.459 & 0.453 & 0.443 & 0.421 \\
\hline & Reducing Sugar & 2.05 & 2.07 & 2.11 & 2.18 & 2.22 & 2.26 \\
\hline & Total Sugar & 2.31 & 2.36 & 2.38 & 2.38 & 2.43 & 2.49 \\
\hline \multirow{6}{*}{ T3 } & Acidity & 0.256 & 0.29 & 0.3 & 0.312 & 0.326 & 0.346 \\
\hline & $\mathrm{pH}$ & 2.75 & 2.7 & 2.66 & 2.58 & 2.53 & 2.48 \\
\hline & TSS $\left({ }^{\circ}\right.$ Brix $)$ & 10.64 & 12.3 & 12.6 & 13.03 & 13.3 & 13.7 \\
\hline & Ascorbic acid & 2.63 & 2.213 & 0.551 & 0.435 & 0.417 & 0.411 \\
\hline & Reducing Sugar & 2.05 & 2.06 & 2.13 & 2.18 & 2.21 & 2.26 \\
\hline & Total Sugar & 2.31 & 2.34 & 2.42 & 2.46 & 2.49 & 2.52 \\
\hline \multirow{6}{*}{$\mathrm{T} 4$} & Acidity & 0.256 & 0.31 & 0.321 & 0.342 & 0.361 & 0.389 \\
\hline & $\mathrm{pH}$ & 2.75 & 2.62 & 2.59 & 2.51 & 2.44 & 2.4 \\
\hline & TSS ( ${ }^{\circ}$ Brix) & 10.64 & 12.03 & 12.23 & 13.2 & 13.56 & 13.9 \\
\hline & Ascorbic acid & 2.63 & 2.51 & 0.54 & 0.424 & 0.401 & 0.394 \\
\hline & Reducing Sugar & 2.05 & 2.12 & 2.16 & 2.21 & 2.25 & 2.30 \\
\hline & Total Sugar & 2.31 & 2.46 & 2.48 & 2.52 & 2.56 & 2.59 \\
\hline
\end{tabular}

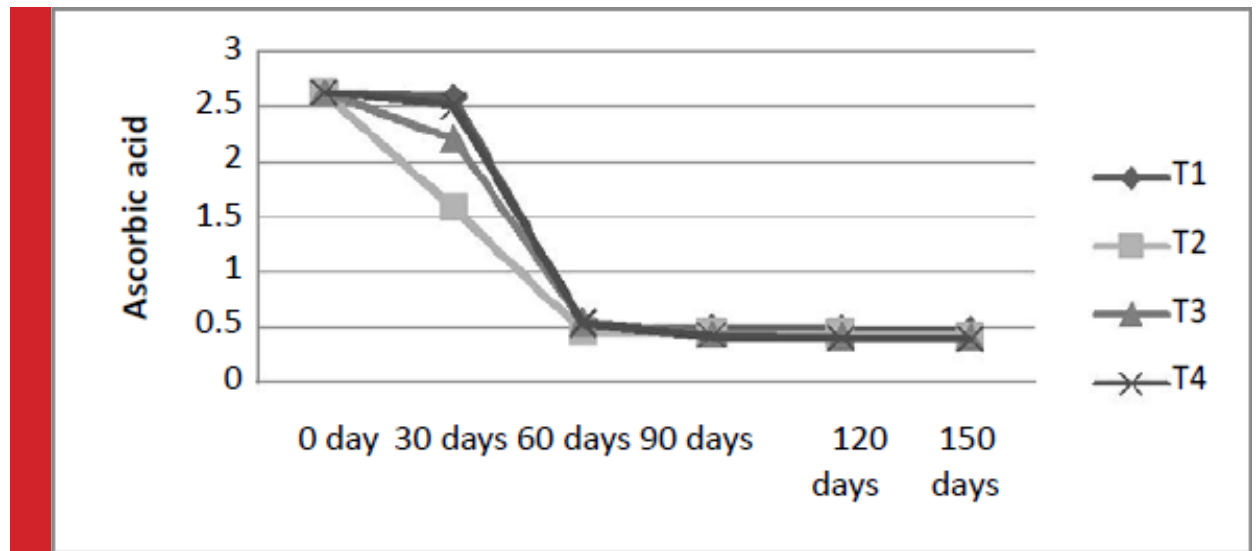

FIGURE 5: Changes in ascorbic acid content of samples during storage period 


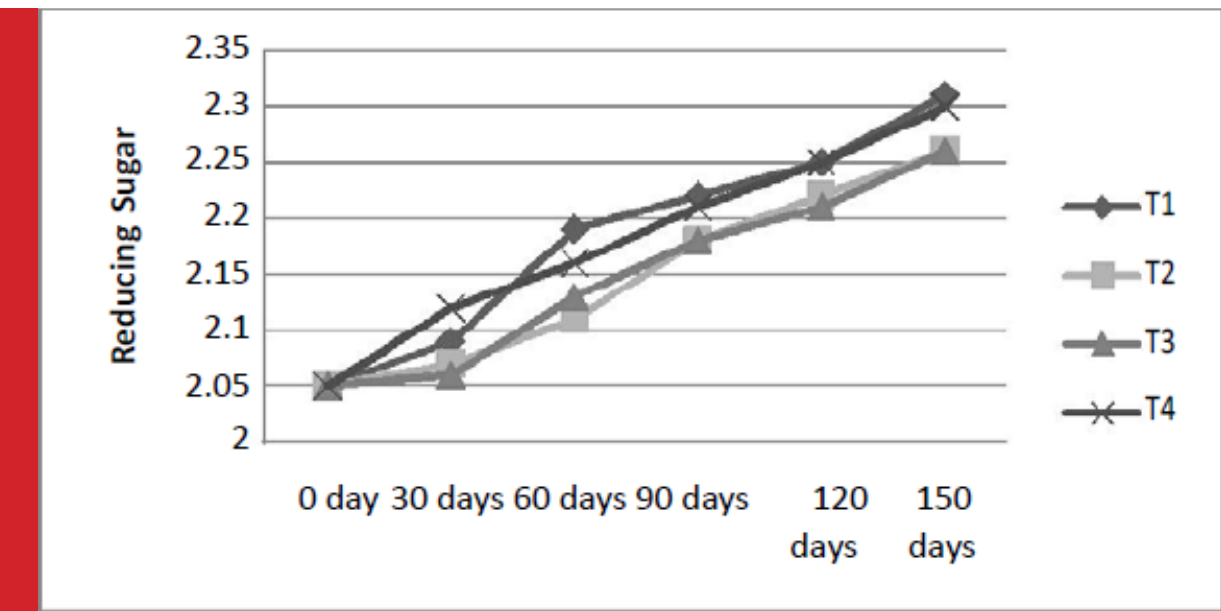

FIGURE 6: Changes in reducing sugar content of samples during storage period

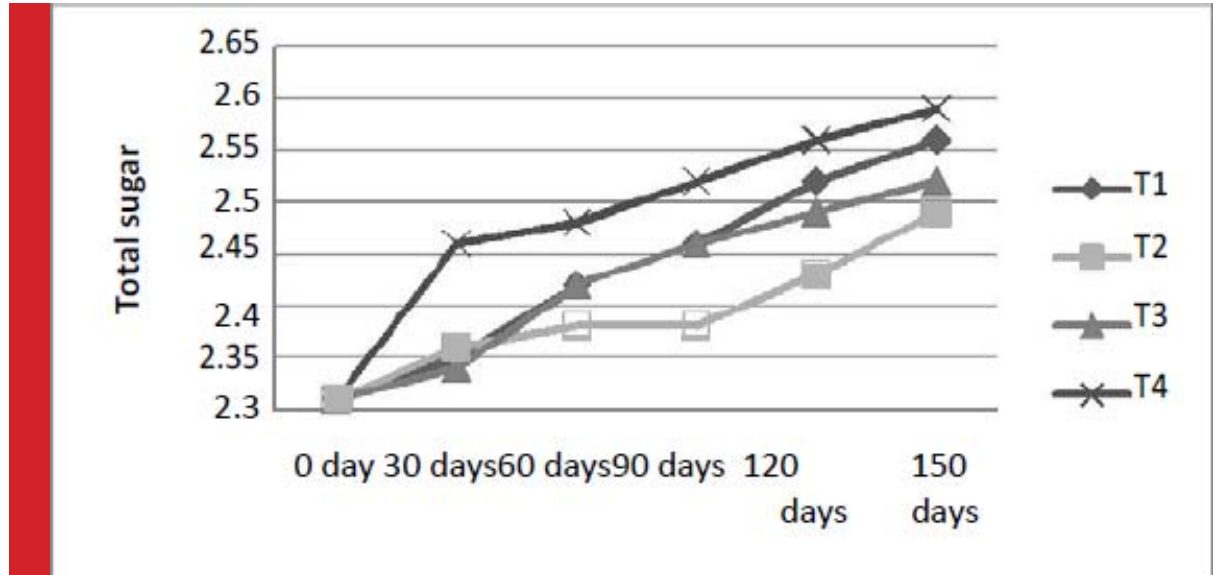

FIGURE 7: Changes in total sugar content of samples during storage period

during the storage of 150 days. These losses of ascorbic acid were attributed to the effect of processing, storage time and exposure to light. The degradation of ascorbic acid in lemon drink may follow ascorbic acid and anaerobic pathways (Moshonas and Shaw, 1989). Similar decreasing trend for ascorbic acid contents in different fruit beverages were also reported by the Ranote and Bains (1982).

The data on reducing sugar for all treatments has been presented in Table 1. For reducing sugars a significant difference was observed during the storage period of 150 days. Reducing sugars of all the samples $T_{1}, T_{2}, T_{3}$ and $\mathrm{T}_{4}$ of lemon drink increased during storage period of 150 days. Reducing sugar tend to increased from initially 2.05 to $2.31,2.26,2.26$ and $2.3 \%$ for samples $\mathrm{T}_{1}$, $\mathrm{T}_{2}, \mathrm{~T}_{3}$ and $\mathrm{T}_{4}$ respectively during 150 days (Fig 6). This gradual increase in reducing sugar during storage for all samples might be due to the hydrolysis of non reducing sugar which continue to increase while non reducing sugar showed decreasing trend in fruit beverages during storage, rise in level of reducing sugar might be due to inversion process of sucrose to glucose and fructose by the acid of the diet drink. Similar observations were also reported by Babsky et al., (1986) and pruthi et al., (1984) that non reducing sugars of drinks is converted in to reducing sugar during storage. The data regarding total sugars revealed that total sugars of all samples of lemon drink increased during the storage period of 150 days. Total sugar tends to increased from initially 2.31 to $2.56,2.49,2.52$ and $2.59 \%$ for the samples $T_{1}, T_{2}, T_{3}$ and $\mathrm{T}_{4}$ respectively during 150 days (Fig 7). A gradual increasing trend in acidity, total soluble solids, reducing sugar and total sugar and a decreasing trend in $\mathrm{pH}$ and ascorbic acid content was noted in all four treatments during storage period of 150 days. The overall results showed that samples without presence of gasses (sealed with vacuum) at $6^{\circ} \mathrm{C}$ gave best results for ascorbic acid retention. 


\section{REFERENCES}

AOAC (1995) Association of Official Analytical Chemists, Official Methods of Analysis (12 ${ }^{\text {th }} \mathrm{ed}$ ) Washington D.C., 16-17.

Babsky J.E., Toribio J.L. and Lozano J.E. (1986). Influence of storage on the composition of clarified apple juice concentrate. Journal of Food Science 51(3): 564-567.

Bhat M.K. (2000). Cellulases and related enzymes in bio-technology. Biotechnology Advances 18: 355-383.

FAOSTAT (2010). Food and Agriculture Organization Statistical Production Yearbook. 2010-2011, FA0, Rome, Italy.

Gonzalez-Molina E., Dominguez-Perles R., Moreno D.A. and Garcia-Viguera C. (2010). Natural bioactive compounds of citrus limon for food and health. Journal of Pharmaceutical and Biomedical Analysis 51(2): 327-345.

Gonzalez-Molina E., Moreno D.A. and Garcia-Viguera C. (2008). Genotype and harvest time influence the phytochemical quality of fine lemon juice (Citrus limon (L.) Burm. F.) for industrial use. Journal of Agriculture and Food Chemistry 56(5): 1669-1675.

Kaunjoso B.W.T. and Luh B.S. (1967). Texture, Pectin and syrup viscosity of canned cling peaches. Food Technology 21(3): 139-142.

Miyake Y., Yamamoto K., Tsujihara N. and Osawa T. (1998). Protective effects of lemon flavonoids on oxidative stress in diabetic rats. Lipids, 33: 689-695.

Moshonas M.G. and Shaw P.E. (1989). Changes in composition of volatile components in aseptically packed orange juice during storage. Journal of Agriculture and Food Chemistry 37(1): 157-161.

Mulero J., Bernabe J., Cerda B., Garcia-Viguera C., Moreno D.A. and Albaladejo M.D. (2012). Variations on cardiovascular risk factors in metabolic syndrome after consume of a citrusbased juice. Clinical Nutrition. (http://dx.doi.org/10.1016/j. clnu.2011.11.014).
Opera GH (2015) In Food and Agriculture Organization Statistical Production Yearbook 2015, FAO, Rome, Italy.

Pruthi J.S., Manan J.K., Teotia M.S., Podhakri-Shnasetty G., Epison WE, Saroja S and Chikkappaji KC (1984). Studies on the utilization of Kinnow and Malta. Journal of Food Science and Technology (India) 21(3): 123-127.

Ranganna S. (1986). Hand Book of Analysis and Quality Control for Fruit and Vegetable Products. Tata McGraw-Hill Publishing Company Limited New Delhi.

Ranote P.S. and Bains G.S. (1982). Juice of kinnow fruit. Indian Food Packer 36(5): 23-33.

Saleem M. (1980). Studies on the preparation of comminuted citrus fruit beverage base. M.Sc. Thesis, University of Agriculture, Faisalabad.

Sarolia D.K. and Mukherjee S. (2002). Comparative efficiency of different preservation methods in keeping quality of lime (Citrus aurantifolia) swingle juice during storage. Haryana Journal Horticulture Science 31(3-4): 185-188.

Singh C., Poonia G.S., and Toor G.S. (1994). Distribution pattern of fruit processing industry in Punjab. Indian Food Packers 8(1): 47.

Vidhya R. and Narain A. (2011). Formulation and Evaluation of Preserved Products Utilizing under Exploited Fruit, Wood Apple (Limonia acidissima). American-Eurasian Journal of Agriculture and Environmental Science 10(1): 112118.

Yu J., Wang L., Walzem R.L., Miller E.G., Pike L.M. and Patil B.S. (2005). Antioxidant activity of citrus limonoids, flavonoids and coumarins. Journal of Agriculture and Food Chemistry 53: 2009-2014.

Zia M.A. (1987). Production and characterization of fruit juice blends of mango, pomegranate and guava. M.Sc. thesis. Department of Food Technology, University of Agriculture, Faisalabad. 